\title{
Grape Seed Proanthocyanidins Inhibit Migration and Invasion of Bladder Cancer Cells by Reversing EMT through Suppression of TGF- $\beta$ Signaling Pathway
}

\author{
Ninggang Yang, ${ }^{1}$ Jing Gao, ${ }^{2}$ Ruizhen $\mathrm{Hou}^{3}{ }^{3}$ Xiaoli Xu, ${ }^{4}$ Ningqiang Yang $\mathbb{D},{ }^{5}$ \\ and Shuangsheng Huang $\mathbb{D}^{6}$ \\ ${ }^{1}$ Department of Urology, The First People's Hospital of Lanzhou City, Lanzhou 730050, China \\ ${ }^{2}$ Hospital of Northwest Minzu University, Lanzhou 730030, China \\ ${ }^{3}$ The First School of Clinical Medicine, Lanzhou University, Lanzhou 730000, China \\ ${ }^{4}$ School of Basic Medicine, Lanzhou University, Lanzhou 730000, China \\ ${ }^{5}$ Department of Urology, Lanzhou University Second Hospital, Lanzhou 730030, China \\ ${ }^{6}$ Medical Department of Northwest Minzu University, Lanzhou 730030, China
}

Correspondence should be addressed to Ningqiang Yang; yangnq0488@163.com and Shuangsheng Huang; huangshsh02@qq.com Received 24 February 2021; Revised 11 June 2021; Accepted 4 July 2021; Published 27 July 2021

Academic Editor: Anderson J. Teodoro

Copyright ( 2021 Ninggang Yang et al. This is an open access article distributed under the Creative Commons Attribution License, which permits unrestricted use, distribution, and reproduction in any medium, provided the original work is properly cited.

Bladder cancer (BC) is the most common cancer of the urinary system. Despite advances in diagnosis and therapy, the prognosis is still poor because of recurrence and metastasis. Epithelial-mesenchymal transition (EMT) is considered to play an important role in the invasion and metastasis of BC. Grape seed proanthocyanidins (GSPs) exhibit chemopreventive and chemotherapeutic activities against several types of cancer. However, their effects and underlying mechanisms on the invasive potential of BC remain unclear. In this study, we found that GSPs inhibited migration, invasion, and MMP-2/-9 secretion of both T24 and 5637 bladder cancer cells at noncytotoxic concentrations. We also discovered that 5637 cells were more suitable than T24 cells for the EMT study. Further study showed that GSPs inhibited EMT by reversing the TGF- $\beta$-induced morphological change and upregulation of mesenchymal markers N-cadherin, vimentin, and Slug as well as downregulation of epithelial markers E-cadherin and ZO-1 in 5637 cells. GSPs also inhibited TGF- $\beta$-induced phosphorylation of Smad2/3, Akt, Erk, and p38 in 5637 cells without affecting the expression of total Smad2/3, Akt, Erk, and p38. Taken together, the results of the present study demonstrate that GSPs effectively inhibit the migration and invasion of $\mathrm{BC}$ cells by reversing EMT through suppression of the TGF- $\beta$ signaling pathway, which indicates that GSPs could be developed as a potential chemopreventive and therapeutic agent against bladder cancer.

\section{Introduction}

Bladder cancer (BC) is the most common cancer of the urinary system. It ranks tenth among 36 cancers worldwide, with an estimated 549,000 new cases and about 200,000 deaths during 2018. Especially in men, it is the sixth most common cancer and the ninth leading cause of cancer death [1]. In China, BC is the 13th most common cancer and the 12th leading cause of cancer death. It is estimated that there were 78,100 new cases and 32,100 cancer death in 2014 [2]. Furthermore, according to Cai et al., both incidence and mortality of BC will continue to increase among some countries and regions in the next 15 years [3]. Despite significant progresses in combined therapies including surgery, chemotherapy, and radiotherapy, BC is still characterized by a poor prognosis and a low survival rate during the past decades, particularly as a result of recurrence and metastasis [4]. Therefore, it is necessary to identify mechanisms underlying $\mathrm{BC}$ development as well as develop novel therapeutic reagents for its treatment.

Epithelial-mesenchymal transition (EMT) is a process in which polarized epithelial cells undergo a phenotypic 
transition that enables them to obtain mesenchymal cells traits. Hallmarks of EMT include the loss of expression of epithelial markers, such as E-cadherin and occludins, and the concomitant increase of mesenchymal markers including $\mathrm{N}$-cadherin and vimentin [5-7]. EMT is considered a pathological process that promotes cancer progression, particularly invasion and metastasis. Through this process, cancer cells detach from the primary tumor and acquire migratory and invasive capabilities as well as resistance to therapy [8-10]. Therefore, inhibition of EMT would be an effective measure to block cancer invasion and metastasis. The most wellcharacterized factor responsible for the induction of EMT by far is TGF- $\beta$. TGF- $\beta$ has a dual role in tumor progression. In the early stage, TGF- $\beta$ is considered as a tumor suppressor by inducing cell differentiation and apoptosis. In the late stage, TGF- $\beta$ contributes to cancer progression by promoting tumor invasion and metastasis, which is related to its induction of EMT $[11,12]$. In bladder cancer, studies have shown that cancer-associated fibroblasts induce bladder cancer cell EMT and invasiveness through secreting TGF- $\beta$ [13]. Therefore, inhibition or reversion of the TGF- $\beta$ signaling pathwaymediated EMT might be an effective measure for bladder cancer treatment.

It is reported that many polyphenolic compounds have anti-EMT activity $[14,15]$. Proanthocyanidins are dimers, trimers, and other oligomers of flavan-3-ols. As a kind of natural polyphenolic compounds, proanthocyanidins have significant antioxidant activities and are rich in grapes, especially in grape seeds [16]. Grape seed proanthocyanidins (GSPs) have been reported to possess chemopreventive and chemotherapeutic potential against several types of cancers. The underlying mechanisms are related to inhibition of proliferation, induction of apoptosis, arrest of cell cycle, inhibition of angiogenesis, and suppression of metastasis [17-19]. GSPs have also been shown to have the ability to reverse the process of EMT [20-22]. However, the effects and underlying mechanisms of GSPs on the invasive potential of BC remain unclear.

In the present study, we investigated the antimetastic activity and associated mechanisms of GSPs against human $\mathrm{BC}$ cells in vitro. Our results show that GSPs inhibit the migration, invasion, and MMP-2/9 secretion of both T24 and 5637 bladder cancer cells. GSPs also inhibit TGF- $\beta$ induced EMT of 5637 cells, which are related to the blocking of the TGF- $\beta$ signaling pathway. Hence, the present study provides scientific evidences supporting GSPs as chemopreventive and chemotherapeutic agents against $\mathrm{BC}$.

\section{Materials and Methods}

2.1. Chemicals and Reagents. Grape seed proanthocyanidins (GSPs) containing $\geq 95 \%$ proanthocyanidins, $\geq 1.8 \%$ proanthocyanidins $\mathrm{B} 2$, and $\geq 60 \%$ oligomers were obtained from Tianjin Jianfeng Natural Product R\&D Co., Ltd. (Tianjin, China). RPMI-1640 culture medium was obtained from Gibco (Thermo Fisher Scientific, Inc., Waltham, MA, USA). Fetal bovine serum (FBS) was purchased from National HyClone (Lanzhou) Bio-engineering Co., Ltd. (Lanzhou, China). Sulforhodamine B (SRB) and gelatin from porcine skin were obtained from Sigma-Aldrich (Merck KGaA, Darmstadt, Germany). Millicell Cell Culture Inserts were obtained from EMD Millipore (Billerica, MA, USA). Matrigel and transforming growth factor- $\beta$ (TGF- $\beta$ ) was purchased from BD Biosciences (Franklin Lakes, NJ, USA). RIPA lysis buffer (protease and phosphatase inhibitors added) was purchased from Beyotime Institute of Biotechnology (Shanghai, China). Primary antibodies directed against $\mathrm{N}$-cadherin, vimentin, $\mathrm{E}$-cadherin, and $\beta$-actin were purchased from Abcam (Cambridge, MA, USA). Primary antibodies directed against ZO-1, Slug, Smad 2/3, p-Smad2 (Ser465/467)/Smad3 (Ser423/425), Akt, p-Akt, p44/42 MAPK (Erk1/2), p-p44/42 MAPK (Erk1/2), p38 MAPK, pp38 MAPK, and horseradish peroxidase-conjugated goat anti-rabbit IgG were purchased from Cell Signaling Technology (Danvers, MA, USA). SuperSignal ${ }^{\mathrm{TM}}$ West Pico PLUS Chemiluminescent Substrate was purchased from Thermo Scientific (Waltham, MA, USA). GSPs were dissolved in DMSO as stock and diluted to appropriate concentrations with RPMI 1640 medium before use. The maximum final concentration of DMSO in cultures was less than $0.5 \%$.

2.2. Cell Culture. Human bladder cancer cell lines T24 and 5637 were obtained from the Type Culture Collection of the Chinese Academy of Sciences (Shanghai, China) and cultured in RPMI 1640 medium supplemented with 10\% FBS at $37^{\circ} \mathrm{C}$ and $5 \% \mathrm{CO}_{2}$.

2.3. Cell Viability Assay. The viability of cells was determined by the SRB assay as previously described [23] with certain modifications. Cells were plated into 96-well plates at a density of $4-6 \times 10^{3}$ cells/well in $100 \mu 11640$ medium supplemented with $10 \%$ FBS. Following incubation at $37^{\circ} \mathrm{C}$ overnight, cells were treated with GSPs at varying concentrations $(0-200 \mu \mathrm{g} / \mathrm{ml})$ for 24,48 , or $72 \mathrm{~h}$. Subsequently, the cultures were fixed with cold $10 \%$ trichloroacetic acid at $4^{\circ} \mathrm{C}$ for $1 \mathrm{~h}$ and washed with water. Next, the plates were air-dried and the fixed cells were stained with $0.4 \%$ SRB at room temperature for $10 \mathrm{~min}$ and washed repeatedly with $0.1 \%$ acetic acid to remove the unbound dye. The bound SRB was dissolved in $1 \%$ Tris ( $\mathrm{pH} 10.5$ ). The optical density was measured at $515 \mathrm{~nm}$ using a microplate reader.

2.4. Cell Migration Assay. Cell migration was assayed in Millicell Cell Culture Inserts using a polycarbonate filter with a pore size of $8 \mu \mathrm{m}$ as previously described [24]. Cells were trypsinized and suspended in a serum-free 1640 medium. A total of $8 \times 10^{4}$ cells in $0.4 \mathrm{ml}$ medium were seeded into the upper chamber of cell culture inserts with various concentrations of GSPs $(0-50 \mu \mathrm{g} / \mathrm{ml})$. The culture inserts were then placed into 24-well plates filled with $0.6 \mathrm{ml} 1640$ medium supplemented with $20 \%$ FBS as a chemoattractant. Following incubation at $37^{\circ} \mathrm{C}$ for $24 \mathrm{~h}$, the nonmigrated cells on the upper surface of the membrane were wiped off with a cotton swab. Cells that had crossed over the inserts were fixed with methanol for $30 \mathrm{~min}$ and then stained with $0.1 \%$ crystal violet for $10 \mathrm{~min}$ at room temperature. Images were captured using light microscopy (magnification, $\times 100$ ). The number of cells that had migrated was counted using the Image J software 
(version 1.52v; National Institutes of Health, Bethesda, MD, USA).

2.5. Cell Invasion Assay. A cell invasion assay was performed as previously described [25]. Briefly, the upper chamber of Millicell Cell Culture Inserts using a polycarbonate filter with a pore size of $8 \mu \mathrm{m}$ was coated with $50 \mu$ l Matrigel diluted $1: 8$ with PBS. Subsequently, $4 \times 10^{5}$ cells in $0.4 \mathrm{ml}$ serum-free 1640 medium with or without GSPs $(0-50 \mu \mathrm{g} / \mathrm{ml})$ were added to the upper chamber. The culture inserts were then placed into 24-well plates. Subsequently, the lower chamber was filled with $0.6 \mathrm{ml} 1640$ medium supplemented with $20 \%$ FBS as a chemoattractant to induce invasion. Following incubation at $37^{\circ} \mathrm{C}$ for $24 \mathrm{~h}$, the culture inserts were removed, and the noninvasive cells on the upper surface of culture inserts were scraped away with a cotton swab. The cells that invaded through the Matrigel were fixed with methanol for $30 \mathrm{~min}$ and then stained with $0.1 \%$ crystal violet for $10 \mathrm{~min}$ at room temperature. Images were captured by light microscopy (magnification, $\times 100$ ), and the number of cells was counted using the Image $\mathrm{J}$ software.

2.6. Gelatin Zymography. The enzymatic activities of MMP-2 and MMP-9 were examined by gelatin zymography as described previously [24]. Subconfluent cells were treated with GSPs $(0-50 \mu \mathrm{g} / \mathrm{ml})$ for $24 \mathrm{~h}$ in a serum-free 1640 medium. Following treatment, the conditioned medium was collected and centrifuged at $300 \times \mathrm{g}$ for $10 \mathrm{~min}$ at $4^{\circ} \mathrm{C}$ to remove cellular debris. The supernatants were incubated with sample buffer (without $\beta$-mercaptoethanol) for $0.5 \mathrm{~h}$ at $37^{\circ} \mathrm{C}$ and then subjected to $7.5 \%$ SDS-PAGE in a gel containing $1 \%$ gelatin. Following electrophoresis, the gels were washed twice with washing buffer $[50 \mathrm{mM}$ Tris- $\mathrm{HCl}$ (pH 7.5), $100 \mathrm{mM} \mathrm{NaCl}$ and 2.5\% Triton X-100] for $1 \mathrm{~h}$ and incubated in a reaction buffer $[50 \mathrm{mM}$ Tris- $\mathrm{HCl}(\mathrm{pH} 7.5)$, $150 \mathrm{mM} \mathrm{NaCl}$ and $10 \mathrm{mM} \mathrm{CaCl}_{2}$ ] at $37^{\circ} \mathrm{C}$ for $36 \mathrm{~h}$. Subsequently, the gels were stained with $0.25 \%$ Coomassie Blue R250 for 30 min and destained for 10 min with $25 \%$ methanol and $7.5 \%$ acetic acid at room temperature. Enzyme activity was visualized as a bright band on a blue background. The band intensities were measured using the Adobe Photoshop CS5 software.

2.7. Western Blot Analysis. After treatment with TGF- $\beta$ or TGF- $\beta$ with or without GSPs for $24 \mathrm{~h}$, cells were lysed using RIPA buffer. Total protein was collected and then quantified using the Bradford assay. Protein was separated via $10 \%$ SDSPAGE ( $40 \mu \mathrm{g}$ protein/lane). Following electrophoresis, the separated proteins were transferred to PVDF membranes. Next, the membranes were probed with the primary antibodies at $4^{\circ} \mathrm{C}$ overnight. Following this, the membranes were incubated with horseradish peroxidase-conjugated secondary antibodies at $4^{\circ} \mathrm{C}$ for $2 \mathrm{~h}$. The desired proteins were detected using SuperSignal West Pico Chemiluminescent Substrate according to the manufacturer's protocol. Bands were quantified using Adobe Photoshop CS5.

2.8. Statistical Analysis. Data were expressed as the mean \pm SD. Statistical significance was determined by Student's $t$ -test and ANOVA using the SPSS software (version 20; SPSS,
Inc., Chicago, IL, USA). $P<0.05$ was considered statistically significant.

\section{Results}

3.1. GSPs Decrease the Viability of BC Cells. The effects of GSPs on the viability of BC cells were examined using the SRB assay. As shown in Figure 1, treatment with different concentrations of GSPs in different times inhibited the viability of both T24 and 5637 cells in a dose-dependent manner. The half-maximal inhibitory concentration values $\left(\mathrm{IC}_{50}\right)$ to T24 cells were $206.8,86.9$, and $56.2 \mu \mathrm{g} / \mathrm{ml}$ for 24,48 , and $72 \mathrm{~h}$. Accordingly, the $\mathrm{IC}_{50}$ values to 5637 cells for 24, 48, and $72 \mathrm{~h}$ were $288.3,98.0$, and $52.6 \mu \mathrm{g} / \mathrm{ml}$, respectively. As treatment with $6.25-50 \mu \mathrm{g} / \mathrm{ml}$ GSPs for $24 \mathrm{~h}$ had no significant inhibitory effects on the viability of both T24 and 5637 cells, we carry out subsequent experiments under these conditions.

3.2. GSPs Inhibit Migration of BC Cells. Cancer cell migration and invasion are the initial and critical steps in the process of cancer metastasis. We then investigated the effects of GSPs on the migration of $\mathrm{BC}$ cells using a transwell migration assay. After stimulated T24 cells with $20 \%$ FBS for $24 \mathrm{~h}$, a large number of cells migrated to the lower side of the chamber. Treatment with different concentrations of GSPs inhibited the FBS-induced migration of T24 cells in a dosedependent manner. The inhibition rates of $12.5,25,50 \mu \mathrm{g} / \mathrm{ml}$ GSPs were $20.7 \%, 42.6 \%$, and $67.5 \%$, respectively (Figure 2(a)). The similar inhibitory effects of GSPs were also observed on 5637 cells. As shown in Figure 2(b), GSPs treatments inhibited migration of 5637 cells dose-dependently with the inhibition rates of $3.1 \%, 38.2 \%$, and $67.9 \%$ for 12.5 , 25 , and $50 \mu \mathrm{g} / \mathrm{ml} \mathrm{GSPs}$, respectively.

3.3. GSPs Inhibit Invasion of BC Cells. The effects of GSPs on the invasive capacity of BC cells were also investigated. As shown in Figure 3(a), the addition of $20 \%$ FBS in the lower chamber significantly induced the invasion of T24 cells. GSPs significantly inhibited FBS-induced invasion of T24 cells dose-dependently. The inhibition rates of GSPs at 12.5, 25, and $50 \mu \mathrm{g} / \mathrm{ml}$ were $19.1 \%, 56.0 \%$, and $80.0 \%$, respectively. Similarly, GSPs treatment for $24 \mathrm{~h}$ also inhibited the invasion of 5637 cells. The inhibition rates of GSPs at 12.5, 25, and $50 \mu \mathrm{g} / \mathrm{ml}$ were $19.8 \%, 28.2 \%$, and $45.1 \%$, respectively (Figure 3(b)).

3.4. GSPs Inhibit the Secretion of MMP-2 and MMP-9 by BC Cells. The secretion of MMPs for extracellular matrix degradation is a key event in the process of tumor metastasis. So we further examined the effects of GSPs on the secretion of MMP-2 and MMP-9 by BC cells. Gelatin zymography showed that MMP-2 and MMP-9 activities in the conditioned medium collected from both T24 and 5637 cells were markedly reduced by GSPs dose-dependently (Figure 4).

3.5. Establishment of TGF- $\beta$-Induced EMT Model in BC Cells. EMT plays an important role in promoting tumor invasion and metastasis. TGF- $\beta$ is one important inducer of EMT. To investigate whether GSPs decreased cancer migration 


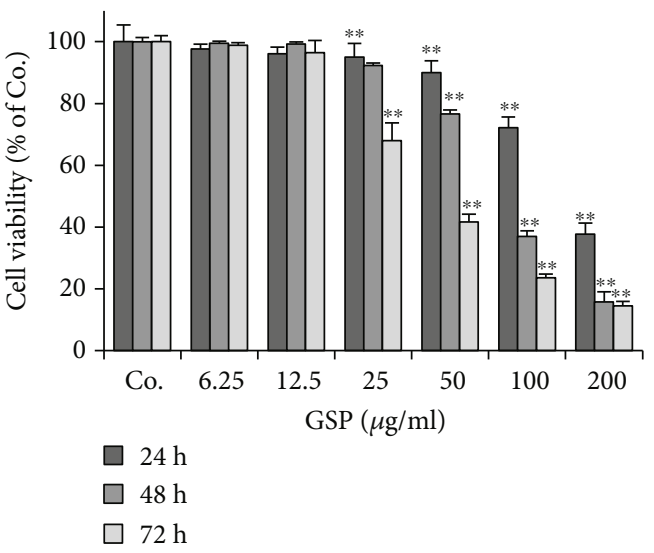

(a)

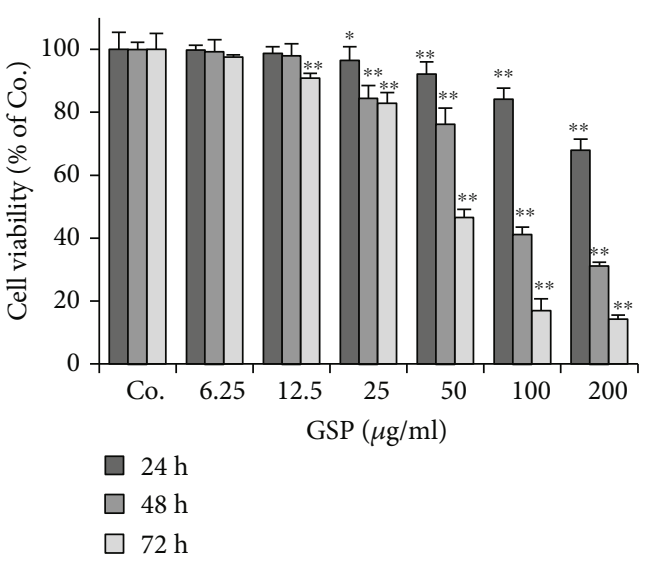

(b)

FIGURE 1: GSPs decrease cell viability of T24 (a) and 5637 (b) cells. After being treated with GSPs for the indicated time, the cell viability was measured with the SRB assay. The data were presented as mean $\pm \mathrm{SD}(n=6) .{ }^{*} P<0.05,{ }^{* *} P<0.01$ vs. control group.

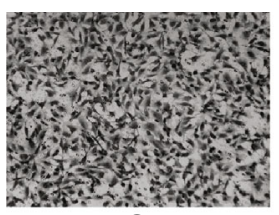

Co.

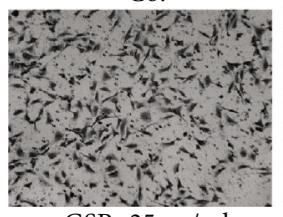

GSPs $25 \mu \mathrm{g} / \mathrm{ml}$

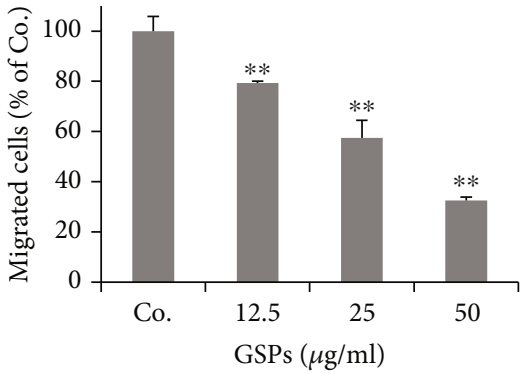

(a)

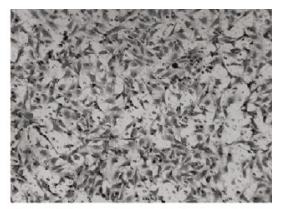

GSPs $12.5 \mu \mathrm{g} / \mathrm{ml}$

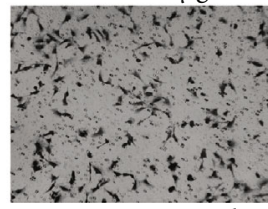

GSPs $50 \mu \mathrm{g} / \mathrm{ml}$

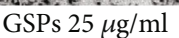

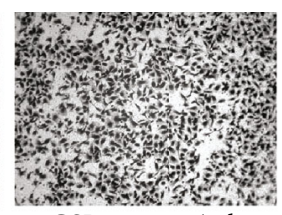

GSPs $12.5 \mu \mathrm{g} / \mathrm{ml}$
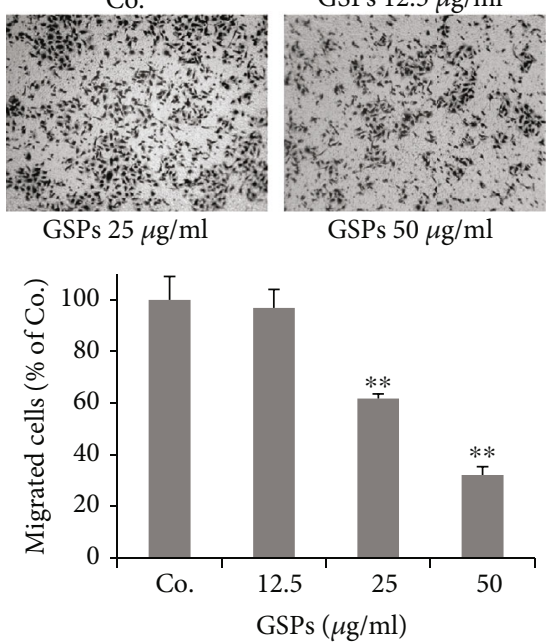

(b)

FIgURE 2: GSPs inhibit migration of T24 (a) and 5637 (b) cells. After incubated with GSPs for $24 \mathrm{~h}$ in the upper chamber of Millicells, cells passed through the membrane were fixed, stained, and counted. Representative images were shown. The data were presented as mean \pm SD $(n=4) .{ }^{* *} P<0.01$ vs. control group.

and invasion through inhibiting EMT, we established the TGF- $\beta$-induced EMT model with T24 and 5637 cells. For this purpose, both T24 and 5637 cells were treated with different concentrations of TGF- $\beta$ for $24 \mathrm{~h}$ and then cell morphology and EMT markers were detected. As shown in Figure 5, treatment with TGF- $\beta$ for $24 \mathrm{~h}$ did not induce obvious morphologic changes of T24 cells (Figure 5(a)). Western blotting results showed that TGF- $\beta$ treatment for $24 \mathrm{~h}$ increased the expression of mesenchymal biomarker vimentin in T24 cells. However, only $5 \mathrm{ng} / \mathrm{ml}$ TGF- $\beta$ enhanced the expression of another mesenchymal biomarker $\mathrm{N}$ - cadherin (Figure 5(b)). We did not detect the expression of epithelial biomarker E-cadherin (data not shown) in T24 cells. In 5637 cells, treatment with different concentrations of TGF- $\beta$ for $24 \mathrm{~h}$ resulted in a morphological change from the initial polygonal epithelial appearance to an elongated mesenchymal morphology (Figure 5(c)). The expression of the mesenchymal marker $\mathrm{N}$-cadherin was increased, while the epithelial marker E-cadherin was decreased by TGF- $\beta$ treatment (Figure 5(d)). These results indicated that 5637 cells were more suitable than T24 cells for the EMT study. Therefore, we selected 5637 cells and $5 \mathrm{ng} / \mathrm{ml}$ 


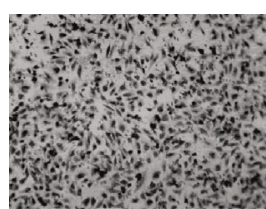

Co.

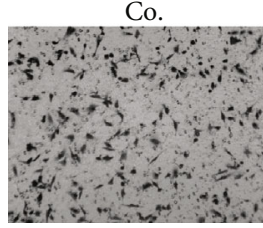

GSPs $25 \mu \mathrm{g} / \mathrm{ml}$

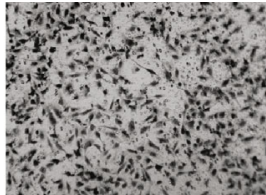

GSPs $12.5 \mu \mathrm{g} / \mathrm{ml}$

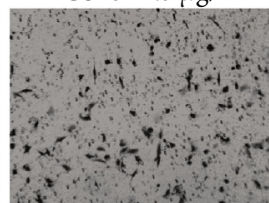

GSPs $50 \mu \mathrm{g} / \mathrm{ml}$

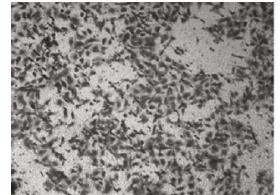

Co.

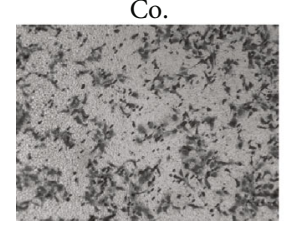

GSPs $25 \mu \mathrm{g} / \mathrm{ml}$

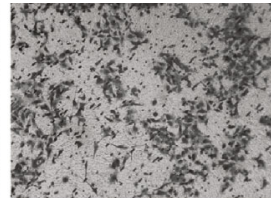

GSPs $12.5 \mu \mathrm{g} / \mathrm{ml}$

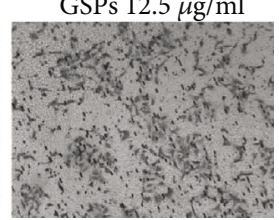

GSPs $50 \mu \mathrm{g} / \mathrm{ml}$

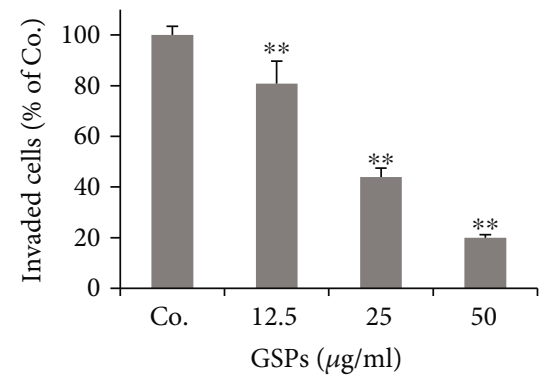

(a)

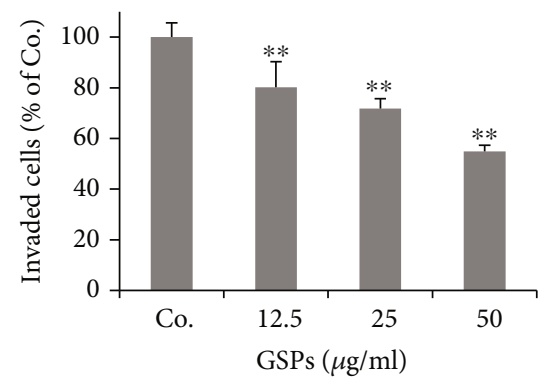

(b)

Figure 3: GSPs inhibit invasion of T24 (a) and 5637 (b) cells. After incubated with GSPs for $24 \mathrm{~h}$ in the upper chamber of Millicells, cells passed through the membrane coated with Matrigel were fixed, stained, and counted. Representative images were shown. The data were presented as mean $\pm \operatorname{SD}(n=4) .{ }^{* *} P<0.01$ vs. control group.
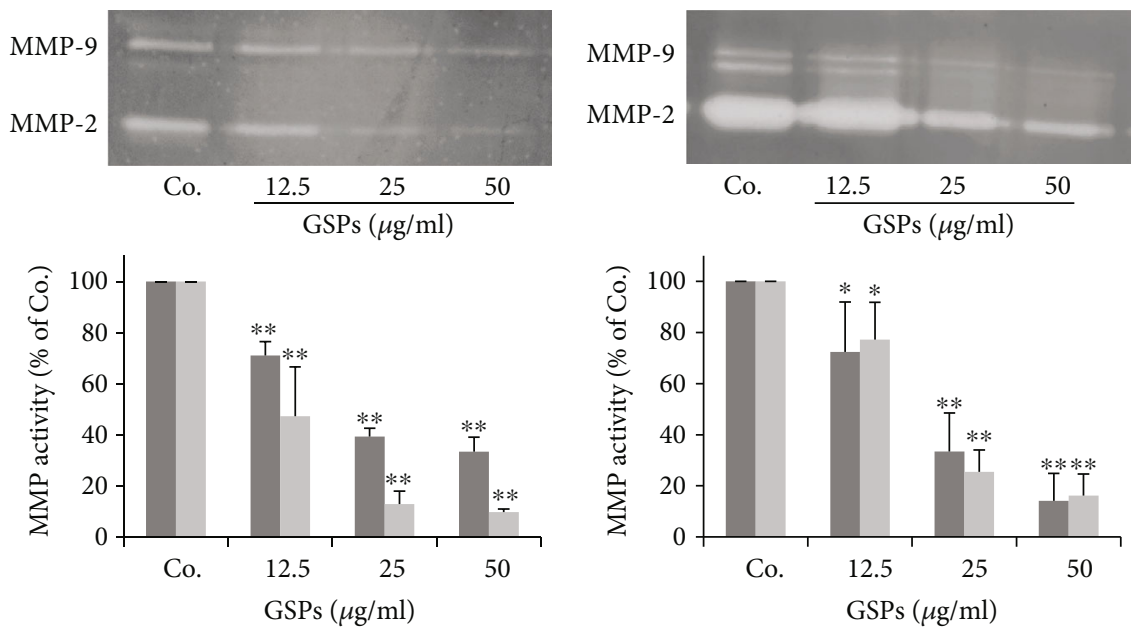

MMP-9

MMP-9

MMP-2

MMP-2

(a)

(b)

Figure 4: GSPs inhibit the secretion of MMP-2/9 of T24 (a) and 5637 (b) cells. Subconfluent cells were treated with different concentrations of GSPs in a serum-free medium for $24 \mathrm{~h}$. The conditioned medium was collected. The activities of MMP-2 and MMP-9 in conditioned medium were detected by gelatin zymography and the results were quantified. The data were presented as mean $\pm \operatorname{SD}(n=3)$. ${ }^{*} P<0.05$, ${ }^{* *} P<0.01$ vs. control group.

TGF- $\beta$ treatment to establish the EMT model induced by TGF- $\beta$.

3.6. GSPs Inhibit TGF- $\beta$-Induced EMT in 5637 Cells. Consistent with results of Figure 5, treatment with TGF- $\beta$ at the concentration of $5 \mathrm{ng} / \mathrm{ml}$ for $24 \mathrm{~h}$ led to a morphological change from an epithelial morphology to a mesenchymal phenotype in 5637 cells. However, GSPs reversed this morphological change induced by TGF- $\beta$ (Figure 6(a)). Results from western blotting also showed that treatment with TGF- $\beta$ at the concentration of $5 \mathrm{ng} / \mathrm{ml}$ for $24 \mathrm{~h}$ upregulated the expression of mesenchymal markers $\mathrm{N}$-cadherin and 


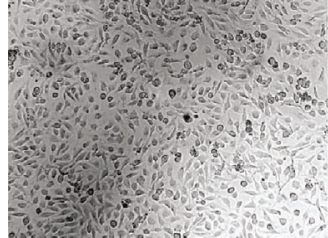

Co.

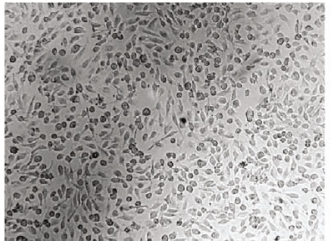

TGF- $\beta 2.5 \mathrm{ng} / \mathrm{ml}$

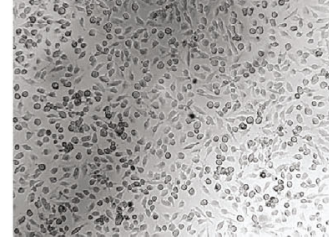

TGF- $\beta 5 \mathrm{ng} / \mathrm{ml}$

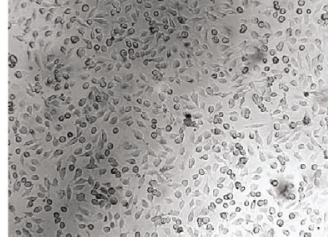

TGF- $\beta 10 \mathrm{ng} / \mathrm{ml}$

(a)

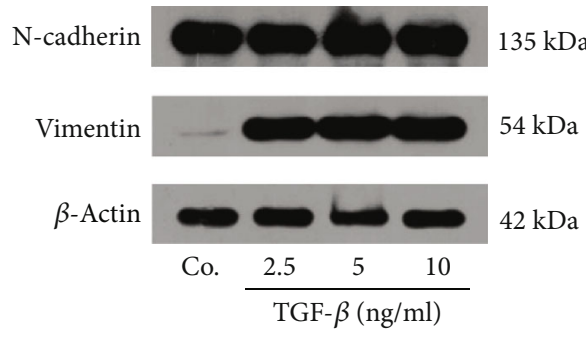

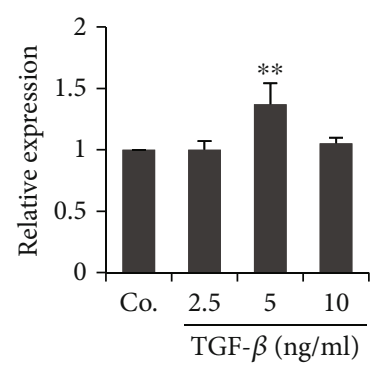

N-cadherin

(b)

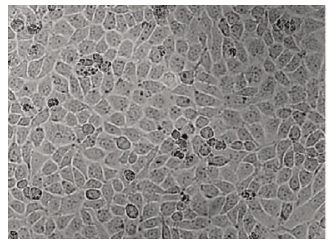

Co.

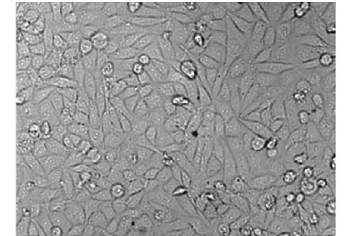

TGF- $\beta 2.5 \mathrm{ng} / \mathrm{ml}$

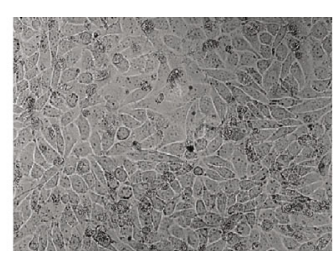

TGF- $\beta 5 \mathrm{ng} / \mathrm{ml}$

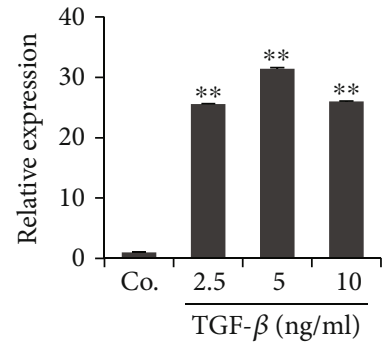

Vimentin

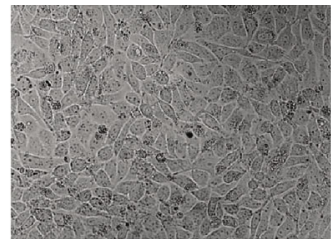

TGF- $\beta 10 \mathrm{ng} / \mathrm{ml}$

(c)

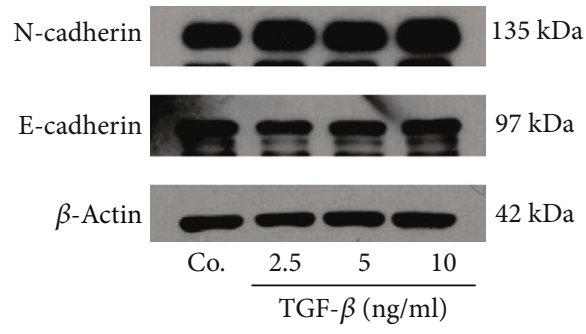

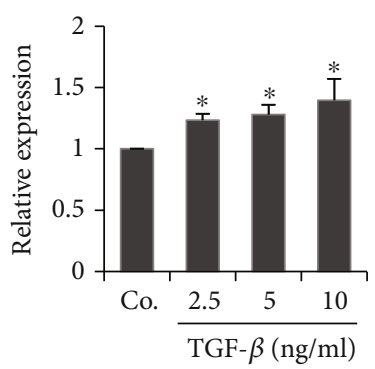

$\mathrm{N}$-cadherin

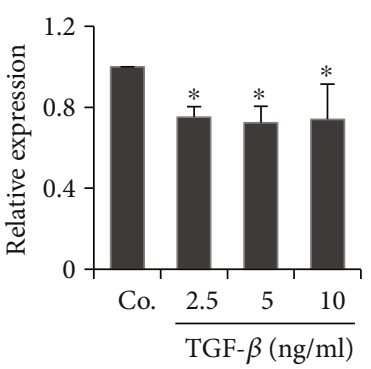

E-cadherin

(d)

FIGURE 5: Establishment of TGF- $\beta$-induced EMT model of BC cells. T24 (a, b) and 5637 (c, d) were treated with TGF- $\beta$ for 24 h. The morphological changes were observed under a phase-contrast microscope and photographed (100x). The level of EMT markers was examined by western blotting and the results were quantified. The data were presented as mean $\pm \mathrm{SD}(n=3) .{ }^{*} P<0.05,{ }^{* *} P<0.01$ vs. control group.

vimentin as well as EMT-related transcription factors Slug but downregulated the expression of epithelial marker Ecadherin and ZO-1 in 5637 cells. GSPs treatment reversed the TGF- $\beta$-induced upregulation of $\mathrm{N}$-cadherin, vimentin, and Slug as well as downregulation of E-cadherin and ZO-1 dose-dependently (Figure 6(b)). These results suggested that GSPs were able to inhibit TGF- $\beta$-induced EMT.

3.7. GSPs Inhibit TGF- $\beta$ Signal Pathway. To elucidate potential molecular mechanisms of GSPs on EMT in 5637 cells, we examined the effects of GSPs on the activation of downstream signal molecules of TGF- $\beta$. As shown in Figure 7, treatment with TGF- $\beta(5 \mathrm{ng} / \mathrm{ml})$ enhanced the phosphorylation of Smad 2/3, Akt, Erk, and p38. GSPs treatment blocked the TGF- $\beta$-induced phosphorylation of Smad $2 / 3$, Akt, Erk, and p38 without affecting the total SMAD2/3, Akt, Erk, and p-38 expression level.

\section{Discussion}

Increasing evidences demonstrated that many natural polyphenolic compounds including resveratrol and curcumin possessed a wide spectrum of pharmacological properties, including antimetastasis activities. The mechanisms of this 


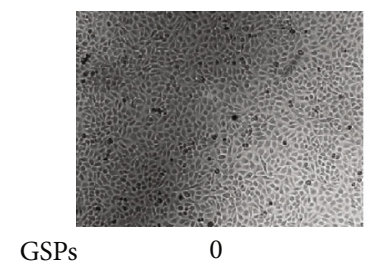

$(\mu \mathrm{g} / \mathrm{ml})$

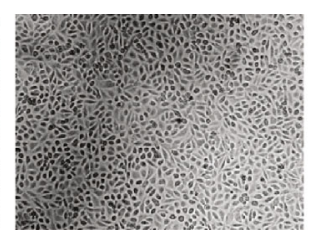

0

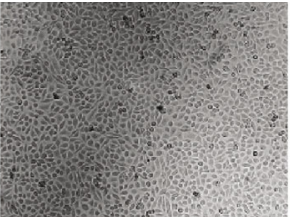

6.25

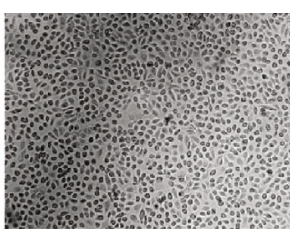

12.5

TGF $(5 \mathrm{ng} / \mathrm{ml})$

(a)
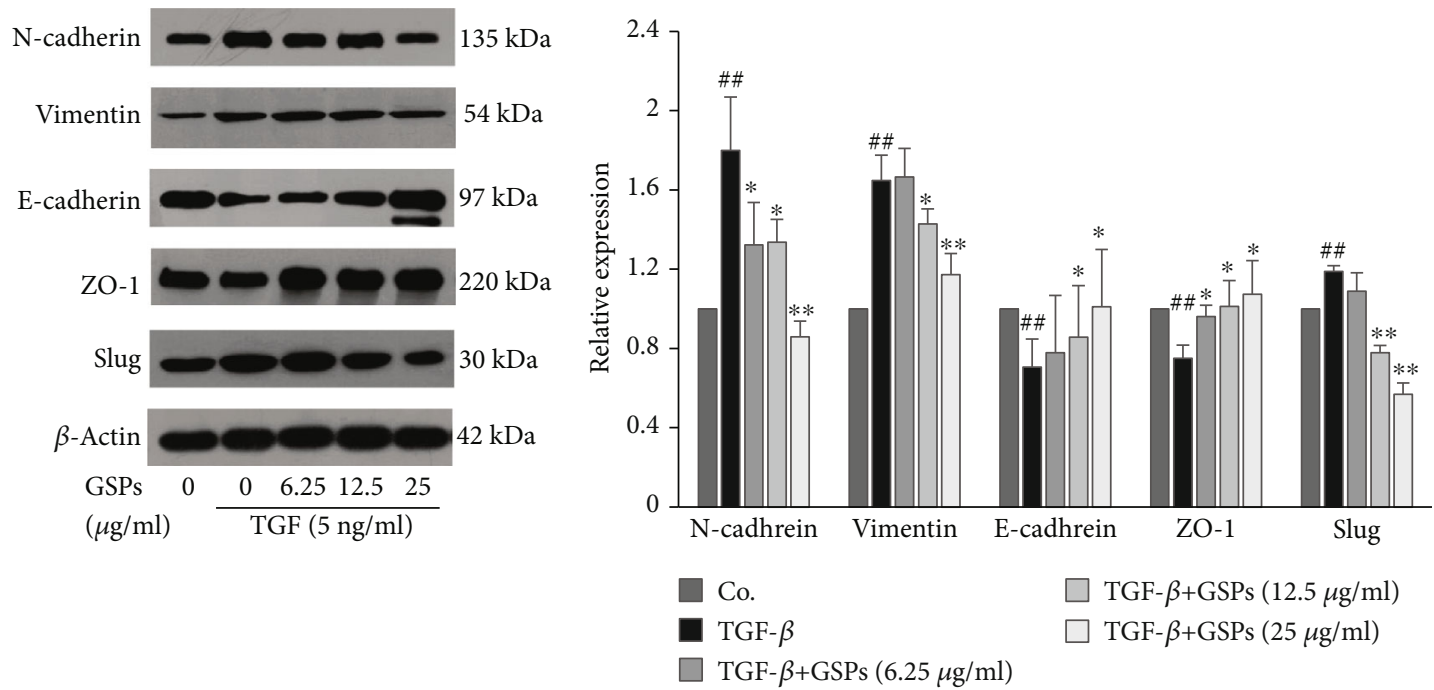

(b)

Figure 6: GSPs inhibit TGF- $\beta$-induced EMT in 5637 cells. 5637 cells were treated with GSPs in the presence or absence of $5 \mathrm{ng} / \mathrm{ml}$ of TGF- $\beta$ for $24 \mathrm{~h}$. (a) The morphological changes were observed under a phase-contrast microscope and photographed (100x). (b) The expression of EMT markers was detected by western blotting and the results were quantified. The data were presented as mean \pm SD $(n=3)$. \#\# $P<0.01$ vs. control group and ${ }^{*} P<0.05,{ }^{* *} P<0.01$ vs. TGF- $\beta$ treatment alone.

action were mainly related to the inhibition of EMT phenotype through suppression of multiple signaling pathways, such as PI-3K/Akt, NF- $\kappa$ B, FAK, and TGF- $\beta 1 /$ SMADs pathway [26-29]. GSPs have also been shown to inhibit the metastasis of various types of cancer including tongue squamous cell carcinoma [30], nonsmall cell lung cancer [31], pancreatic cancer [21], and lung cancer [32]. The molecular targets of GSPs include NF- $\kappa \mathrm{B}, \mathrm{PI} 3 \mathrm{~K} / \mathrm{Akt}$, and MAPK signaling pathway. The goal of this study was to investigate the antimetastatic activity and associated mechanisms of GSPs against human BC cells in vitro. We found that GSPs inhibited the migration, invasion, and secretion of MMP-2/9 of T24 and 5637 cells at noncytotoxic concentrations.

EMT has an important role in promoting the invasion and metastasis of cancer cells. This process is regulated by multiple signaling molecules. Among them, TGF- $\beta$ is a potent stimulator of EMT [33]. Therefore, we select TGF- $\beta$ to establish the EMT model of bladder cancer cells. Although Both T24 and 5637 cells are derived from bladder cancer, we found that morphology change induced by TGF- $\beta$ was more obvious in 5637 cells than in T24 cells. Moreover, in T24 cells, TGF- $\beta$ treatment only increased the expression of the mesenchymal marker $\mathrm{N}$-cadherin and vimentin. No expression of epithelial marker E-cadherin was detected. Unlike T24 cells, treatment of 5637 cells with TGF- $\beta$ resulted in the increased expression of $\mathrm{N}$-cadherin, at the same time, the reduced expression of E-cadherin. The results were consistent with previous studies $[34,35]$. Further studies showed that treatment 5637 cells with TGF- $\beta$ for $24 \mathrm{~h}$ led to the increased expression of $\mathrm{N}$-cadherin, vimentin, and Slug and decreased of E-cadherin and ZO-1, indicating the occurrence of EMT. All the results indicated that 5637 cells were better suited for EMT study than T24 cells. Therefore, we selected 5637 to establish the TGF- $\beta$-induced EMT model.

It has been reported that GSPs inhibit EMT in head and neck cutaneous squamous cell carcinoma cells and pancreatic cancer cells $[20,21]$. However, whether GSPs can also inhibit EMT in BC cells remains to be explored. In the present study, we found that treatment with GSPs reversed the TGF- $\beta$-induced morphological changes as well as the expression of EMT markers. These suggest that GSPs have the ability to inhibit EMT in 5637 cells and that this may be one of the possible mechanisms through which GSPs inhibit the migration and invasion of BC cells.

It is reported that TGF- $\beta$ induces EMT through a Smaddependent canonical pathway and the Smad-independent noncanonical pathway. In the Smad-dependent pathway, the binding of TGF- $\beta$ to cell surface receptor results the phosphorylation and activation of Smad2 and/or Smad3. The receptor-activated $\mathrm{Smad} 2$ and/or Smad3 then form 

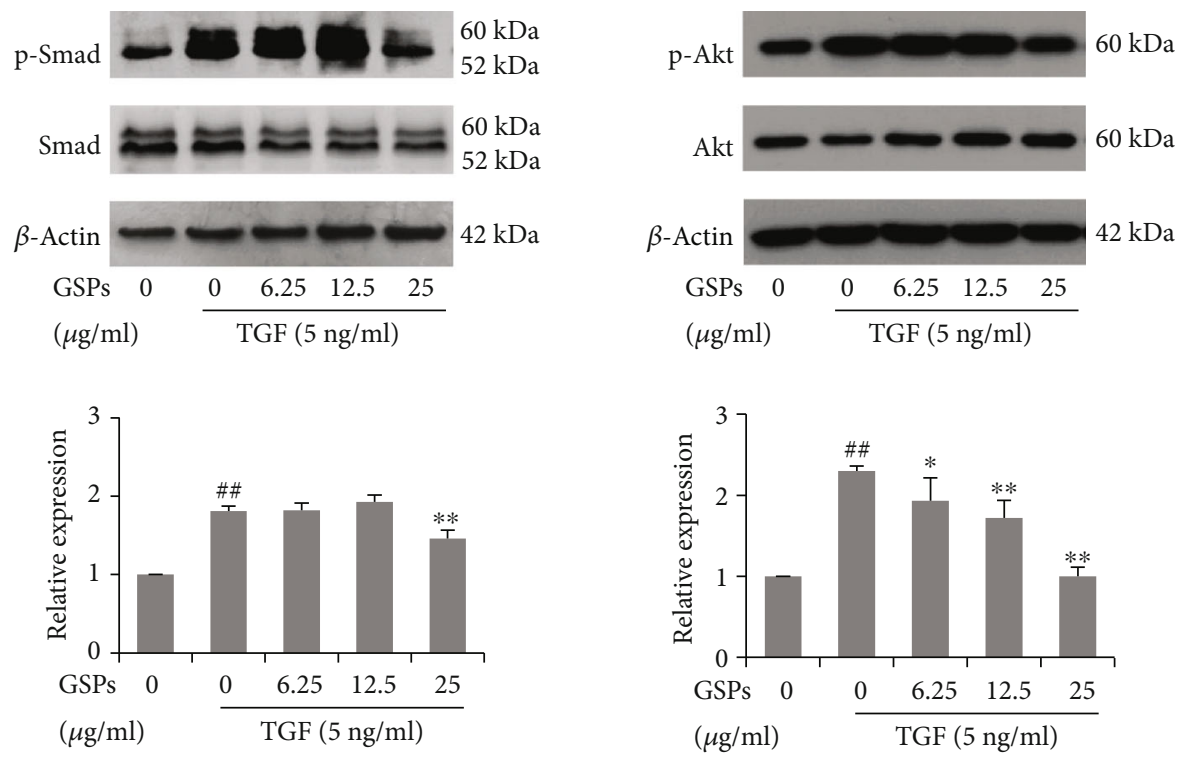

p-Smad/Smad

p-Akt/Akt
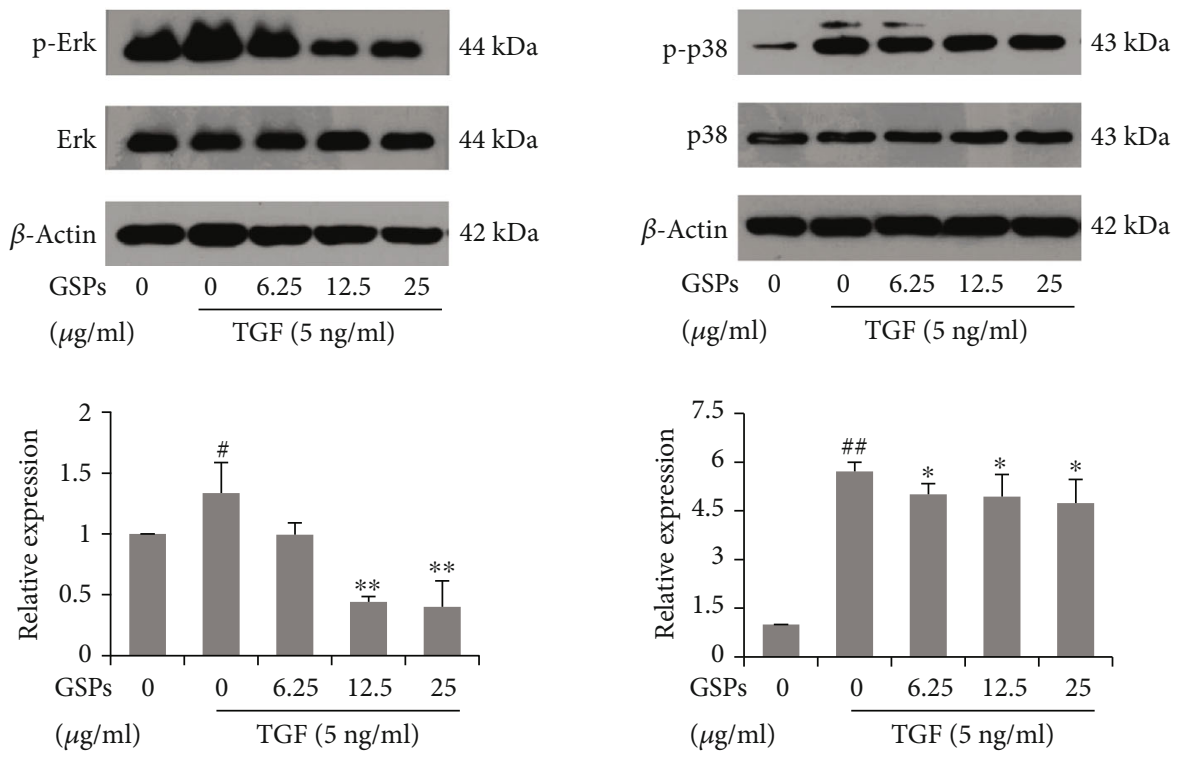

p-Erk/Erk

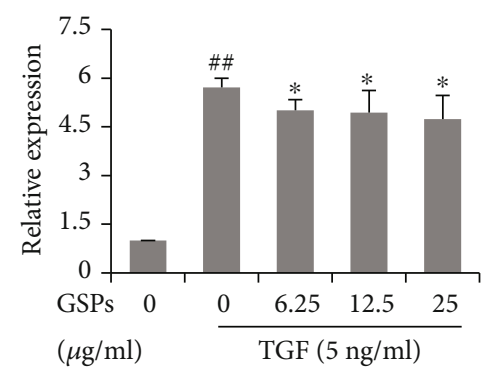

p-p38/p38

FIGURE 7: GSPs inhibit the TGF- $\beta$ signal pathway. 5637 cells were treated with GSPs in the presence or absence of $5 \mathrm{ng} / \mathrm{ml}$ of TGF- $\beta$ for $24 \mathrm{~h}$. The expression of indicated signaling molecules was detected by western blotting and the results were quantified. The data were presented as mean \pm SD $(n=3)$. ${ }^{\#} P<0.05$, ${ }^{\# \# ~} P<0.01$ vs. control group and ${ }^{*} P<0.05,{ }^{* *} P<0.01$ vs. TGF- $\beta$ treatment alone.

Smad complexes with Smad4 and translocate into the nucleus to regulate transcription of target genes that mediate EMT. In addition to the Smad signaling pathways, TGF- $\beta$ also induces EMT in certain types of cells through Smadindependent, noncanonical pathway, which involves the activation of other signaling pathways such as RHO-like GTPases, PI3K-Akt, and MAPK (including ERK, p38, and JNK) [36-38]. Therefore, many natural compounds were reported to inhibit EMT through targeting TGF- $\beta$ signaling. Lee et al. reported that Farnesol, a fragrant component of essential oils, inhibited TGF- $\beta$-induced EMT through block- ing the PI3K/Akt/mTOR signaling pathway in lung cancer cells [39]. Bergamottin, a naturally occurring furanocoumarin, suppressed the metastasis of lung cancer cells through inhibiting the TGF-mediated EMT process by blocking the activation of PI3K/Akt/mTOR signaling [40]. In the present study, treatment with TGF- $\beta$ induced the phosphorylation of Smad2/3, Akt, Erk, and p38 in 5637 cells, suggesting that both Smad-dependent and non-Smad-dependent signaling pathways are related to TGF- $\beta$ induced EMT. GSPs blocked the TGF- $\beta$-induced phosphorylation of Smad2/3, Akt, Erk, and p38 in 5637 cells but did not affect the total expression 
levels of these signal molecules, indicating that the reverse of TGF- $\beta$-induced EMT by GSPs is associated with the suppression of the TGF- $\beta$ signaling pathway.

However, it is important to note that although our results have demonstrated that GSPs inhibit EMT through suppression of the TGF- $\beta$ signaling pathway. It would make the results more convincing to further explore the mechanisms of GSPs by blocking or overexpressing the expression of downstream effectors of TGF- $\beta$ signaling, such as Smad, Akt, p38 MAPK, and Erk, using siRNAs. Moreover, many studies have shown that in addition to TGF- $\beta$, EMT can be initiated by a variety of signaling molecules, including microRNA [41, 42]. It is necessary to establish EMT models induced by other signaling molecules to explore the effects and mechanisms of GSPs. In addition, this is a preliminary study on cell culture. Other BC-derived cell lines and in vivo studies will be needed in the future to further confirm the findings.

\section{Conclusions}

In conclusion, the results of our study indicate that GSPs inhibit migration and invasion of bladder cancer cells by reversing EMT through suppression of the TGF- $\beta$ signaling pathway. Our data suggest that GSPs may be developed as a potential chemopreventive and therapeutic agent against bladder cancer.

\section{Data Availability}

The data used to support the findings of this study are included within the article.

\section{Conflicts of Interest}

The authors declare no conflict of interest.

\section{Authors' Contributions}

Ninggang Yang and Jing Gao contributed equally to this work.

\section{Acknowledgments}

This study was supported by grants from the Program of Innovation and Entrepreneurship for Talents of Lanzhou City (No. 2015-RC-26), the Guiding Plan Project of Science and Technology Development of Lanzhou City (No. 2019ZD-6), the Fundamental Research Funds for the Central Universities (No. 31920180135), and the National Natural Science Foundation of China (No. 81260330).

\section{References}

[1] F. Bray, J. Ferlay, I. Soerjomataram, R. L. Siegel, L. A. Torre, and A. Jemal, "Global cancer statistics 2018: GLOBOCAN estimates of incidence and mortality worldwide for 36 cancers in 185 countries," CA: a Cancer Journal for Clinicians, vol. 68, no. 6, pp. 394-424, 2018.
[2] Y. T. He, D. J. Li, D. Liang et al., "Incidence and mortality of bladder cancer in China, 2014," Zhonghua Zhong Liu Za Zhi, vol. 40, no. 9, pp. 647-652, 2018.

[3] Q. Cai, Y. Chen, S. Xin et al., "Temporal trends of bladder cancer incidence and mortality from 1990 to 2016 and projections to 2030," Translational Andrology and Urology, vol. 9, no. 2, pp. 153-165, 2020.

[4] M. A. Knowles and C. D. Hurst, "Molecular biology of bladder cancer: new insights into pathogenesis and clinical diversity," Nature Reviews. Cancer, vol. 15, no. 1, pp. 25-41, 2015.

[5] R. Kalluri and R. A. Weinberg, "The basics of epithelialmesenchymal transition," The Journal of Clinical Investigation, vol. 119, no. 6, pp. 1420-1428, 2009.

[6] J. P. Thiery, H. Acloque, R. Y. Huang, and M. A. Nieto, "Epithelial-mesenchymal transitions in development and disease," Cell, vol. 139, no. 5, pp. 871-890, 2009.

[7] M. A. Nieto, R. Y. Huang, R. A. Jackson, and J. P. Thiery, "EMT: 2016," Cell, vol. 166, no. 1, pp. 21-45, 2016.

[8] X. Ye and R. A. Weinberg, "Epithelial-mesenchymal plasticity: a central regulator of cancer progression," Trends in Cell Biology, vol. 25, no. 11, pp. 675-686, 2015.

[9] V. Mittal, "Epithelial mesenchymal transition in tumor metastasis," Annual Review of Pathology, vol. 13, no. 1, pp. 395-412, 2018.

[10] I. Pastushenko and C. Blanpain, "EMT transition states during tumor progression and metastasis," Trends in Cell Biology, vol. 29, no. 3, pp. 212-226, 2019.

[11] R. Derynck, R. J. Akhurst, and A. Balmain, “TGF- $\beta$ signaling in tumor suppression and cancer progression," Nature Genetics, vol. 29, no. 2, pp. 117-129, 2001.

[12] J. Massagué, “TGF $\beta$ in Cancer," Cell, vol. 134, no. 2, pp. 215230, 2008.

[13] J. Zhuang, Q. Lu, B. Shen et al., “TGF $\beta 1$ secreted by cancerassociated fibroblasts induces epithelial- mesenchymal transition of bladder cancer cells through lncRNA-ZEB2NAT," Scientific Reports, vol. 5, no. 1, article 11924, 2015.

[14] L. Zhang, X. Wang, and M. Lai, "Modulation of epithelial-tomesenchymal cancerous transition by natural products," Fitoterapia, vol. 106, pp. 247-255, 2015.

[15] B. Salehi, E. M. Varoni, M. Sharifi-Rad et al., "Epithelial-mesenchymal transition as a target for botanicals in cancer metastasis," Phytomedicine, vol. 55, pp. 125-136, 2019.

[16] J. Shi, J. Yu, J. E. Pohorly, and Y. Kakuda, "Polyphenolics in grape seeds-biochemistry and functionality," Journal of Medicinal Food, vol. 6, no. 4, pp. 291-299, 2003.

[17] V. Nandakumar, T. Singh, and S. K. Katiyar, "Multi-targeted prevention and therapy of cancer by proanthocyanidins," Cancer Letters, vol. 269, no. 2, pp. 378-387, 2008.

[18] M. Kaur, C. Agarwal, and R. Agarwal, "Anticancer and cancer chemopreventive potential of grape seed extract and other grape-based products," The Journal of Nutrition, vol. 139, no. 9, pp. 1806S-1812S, 2009.

[19] S. K. Katiyar and M. Athar, "Grape seeds: ripe for cancer chemoprevention," Cancer Prevention Research (Philadelphia, Pa.), vol. 6, no. 7, pp. 617-621, 2013.

[20] Q. Sun, R. Prasad, E. Rosenthal, and S. K. Katiyar, "Grape seed proanthocyanidins inhibit the invasive potential of head and neck cutaneous squamous cell carcinoma cells by targeting EGFR expression and epithelial-to-mesenchymal transition," BMC Complementary and Alternative Medicine, vol. 11, no. 1, p. 134, 2011. 
[21] R. Prasad and S. K. Katiyar, "Grape seed proanthocyanidins inhibit migration potential of pancreatic cancer cells by promoting mesenchymal-to-epithelial transition and targeting NF- $\kappa$ B," Cancer Letters, vol. 334, no. 1, pp. 118-126, 2013.

[22] Y. Y. Luan, Z. M. Liu, J. Y. Zhong, R. Y. Yao, and H. S. Yu, "Effect of grape seed proanthocyanidins on tumor vasculogenic mimicry in human triple-negative breast cancer cells," Asian Pacific Journal of Cancer Prevention, vol. 16, no. 2, pp. 531-535, 2015.

[23] V. Vichai and K. Kirtikara, "Sulforhodamine B colorimetric assay for cytotoxicity screening," Nature Protocols, vol. 1, no. 3, pp. 1112-1116, 2006.

[24] S. Huang, N. Yang, Y. Liu et al., "Grape seed proanthocyanidins inhibit angiogenesis via the downregulation of both vascular endothelial growth factor and angiopoietin signaling," Nutrition Research, vol. 32, no. 7, pp. 530-536, 2012.

[25] A. Albini, Y. Iwamoto, H. K. Kleinman et al., "A rapid in vitro assay for quantitating the invasive potential of tumor cells," Cancer Research, vol. 47, no. 12, pp. 3239-3245, 1987.

[26] C. Buhrmann, M. Yazdi, B. Popper, A. B. Kunnumakkara, B. B. Aggarwal, and M. Shakibaei, "Induction of the epithelial-tomesenchymal transition of human colorectal cancer by human TNF- $\beta$ (lymphotoxin) and its reversal by resveratrol," Nutrients, vol. 11, no. 3, p. 704, 2019.

[27] C. Buhrmann, P. Shayan, P. Kraehe, B. Popper, A. Goel, and M. Shakibaei, "Resveratrol induces chemosensitization to 5fluorouracil through up-regulation of intercellular junctions, epithelial-to-mesenchymal transition and apoptosis in colorectal cancer," Biochemical Pharmacology, vol. 98, no. 1, pp. 51-68, 2015.

[28] S. Toden, Y. Okugawa, T. Jascur et al., "Curcumin mediates chemosensitization to 5-fluorouracil through miRNAinduced suppression of epithelial-to-mesenchymal transition in chemoresistant colorectal cancer," Carcinogenesis, vol. 36, no. 3, pp. 355-367, 2015.

[29] C. Buhrmann, P. Kraehe, C. Lueders, P. Shayan, A. Goel, and M. Shakibaei, "Curcumin suppresses crosstalk between colon cancer stem cells and stromal fibroblasts in the tumor microenvironment: potential role of EMT," PLoS One, vol. 9, no. 9, article e107514, 2014.

[30] N. Yang, J. Gao, X. Cheng et al., "Grape seed proanthocyanidins inhibit the proliferation, migration and invasion of tongue squamous cell carcinoma cells through suppressing the protein kinase $\mathrm{B} /$ nuclear factor- $\kappa \mathrm{B}$ signaling pathway," International Journal of Molecular Medicine, vol. 40, no. 6, pp. 1881-1888, 2017.

[31] T. Punathil and S. K. Katiyar, "Inhibition of non-small cell lung cancer cell migration by grape seed proanthocyanidins is mediated through the inhibition of nitric oxide, guanylate cyclase, and ERK1/2," Molecular Carcinogenesis, vol. 48, no. 3, pp. 232-242, 2009.

[32] Y. Zhou, X. Ye, Y. Shi, K. Wang, and D. Wan, "Grape seed proanthocyanidins inhibits the invasion and migration of A549 lung cancer cells," Xi Bao Yu Fen Zi Mian Yi Xue Za Zhi, vol. 32, no. 2, pp. 173-176, 2016.

[33] J. Chen, Z. Y. Ding, S. Li et al., "Targeting transforming growth factor- $\beta$ signaling for enhanced cancer chemotherapy," Theranostics, vol. 11, no. 3, pp. 1345-1363, 2021.

[34] Z. Adhim, T. Matsuoka, T. Bito et al., "In vitro and in vivo inhibitory effect of three Cox-2 inhibitors and epithelial-tomesenchymal transition in human bladder cancer cell lines," British Journal of Cancer, vol. 105, no. 3, pp. 393-402, 2011.
[35] T. Zeng, L. Peng, C. Chao et al., "miR-451 inhibits invasion and proliferation of bladder cancer by regulating EMT," International Journal of Clinical and Experimental Pathology, vol. 7, no. 11, pp. 7653-7662, 2014.

[36] D. M. Gonzalez and D. Medici, "Signaling mechanisms of the epithelial-mesenchymal transition," Science signaling, vol. 7, no. 344, p. re8, 2014.

[37] S. Lamouille, J. Xu, and R. Derynck, "Molecular mechanisms of epithelial-mesenchymal transition," Nature Reviews. Molecular Cell Biology, vol. 15, no. 3, pp. 178-196, 2014.

[38] Y. Tsubakihara and A. Moustakas, "Epithelial-mesenchymal transition and metastasis under the control of transforming growth factor $\beta$," International Journal of Molecular Sciences, vol. 19, no. 11, p. 3672, 2018.

[39] J. H. Lee, A. Chinnathambi, S. A. Alharbi, O. H. M. Shair, G. Sethi, and K. S. Ahn, "Farnesol abrogates epithelial to mesenchymal transition process through regulating Akt/mTOR pathway," Pharmacological Research, vol. 150, article 104504, 2019.

[40] J. H. Ko, D. Nam, J. Y. Um, S. H. Jung, G. Sethi, and K. S. Ahn, "Bergamottin suppresses metastasis of lung cancer cells through abrogation of diverse oncogenic signaling cascades and epithelial-to-mesenchymal transition," Molecules, vol. 23, no. 7, p. 1601, 2018.

[41] R. Y. Hammouz, D. Kołat, Ż. Kałuzińska, E. Płuciennik, and A. K. Bednarek, "MicroRNAs: their role in metastasis, angiogenesis, and the potential for biomarker utility in bladder carcinomas," Cancers (Basel), vol. 13, no. 4, p. 891, 2021.

[42] M. Ashrafizadeh, K. Hushmandi, M. Hashemi et al., "Role of microRNA/epithelial-to-mesenchymal transition axis in the metastasis of bladder cancer," Biomolecules, vol. 10, no. 8, p. $1159,2020$. 